Béatrice Morio, Jean-François Hocquette, Christophe Montaurier, Yves Boirie, Corinne Bouteloup-Demange, Caroline McCormack, Nicole Fellmann, Bernard Beaufrère and Patrick Ritz

Am J Physiol Endocrinol Metab 280:143-149, 2001.

You might find this additional information useful...

This article cites 36 articles, 16 of which you can access free at:

http://ajpendo.physiology.org/cgi/content/full/280/1/E143\#BIBL

This article has been cited by 4 other HighWire hosted articles:

Effects of trans MUFA from dairy and industrial sources on muscle mitochondrial function and insulin sensitivity

A.-L. Tardy, C. Giraudet, P. Rousset, J.-P. Rigaudiere, B. Laillet, S. Chalancon, J. Salles, O.

Loreau, J.-M. Chardigny and B. Morio

J. Lipid Res., July 1, 2008; 49 (7): 1445-1455.

[Abstract] [Full Text] [PDF]

Diets High in Sugar, Fat, and Energy Induce Muscle Type-Specific Adaptations in Mitochondrial Functions in Rats

E. Chanseaume, C. Malpuech-Brugere, V. Patrac, G. Bielicki, P. Rousset, K. Couturier, J. Salles,

J.-P. Renou, Y. Boirie and B. Morio

J. Nutr., August 1, 2006; 136 (8): 2194-2200.

[Abstract] [Full Text] [PDF]

Metabolic Consequences of Muscle Disuse Atrophy

T. P. Stein and C. E. Wade

J. Nutr., July 1, 2005; 135 (7): 1824S-1828S.

[Abstract] [Full Text] [PDF]

Effect of ovarian hormones on mitochondrial enzyme activity in the fat oxidation pathway of skeletal muscle

S. E. Campbell and M. A. Febbraio

Am J Physiol Endocrinol Metab, October 1, 2001; 281 (4): E803-E808.

[Abstract] [Full Text] [PDF]

Medline items on this article's topics can be found at http://highwire.stanford.edu/lists/artbytopic.dtl on the following topics:

Biochemistry .. Fats

Biochemistry .. Fatty Acids

Biochemistry ... Palmitate

Medicine .. Aging Society

Medicine .. Body Fat

Medicine .. Exercise

Updated information and services including high-resolution figures, can be found at:

http://ajpendo.physiology.org/cgi/content/full/280/1/E143

Additional material and information about AJP - Endocrinology and Metabolism can be found at: http://www.the-aps.org/publications/ajpendo

This information is current as of September 3, 2010 .

AJP - Endocrinology and Metabolism publishes results of original studies about endocrine and metabolic systems on any level of organization. It is published 12 times a year (monthly) by the American Physiological Society, 9650 Rockville Pike, Bethesda MD 20814-3991. Copyright @ 2001 by the American Physiological Society. ISSN: 0193-1849, ESSN: 1522-1555. Visit our website at http://www.the-aps.org/. 


\title{
Muscle fatty acid oxidative capacity is a determinant of whole body fat oxidation in elderly people
}

\author{
BÉATRICE MORIO, ${ }^{1}$ JEAN-FRANÇOIS HOCQUETTE, ${ }^{3}$ CHRISTOPHE MONTAURIER, ${ }^{1}$ \\ YVES BOIRIE, ${ }^{1}$ CORINNE BOUTELOUP-DEMANGE,${ }^{1}$ CAROLINE MCCORMACK, ${ }^{1}$ \\ NICOLE FELLMANN, ${ }^{2}$ BERNARD BEAUFRÈEE, ${ }^{1}$ AND PATRICK RITZ ${ }^{1}$ \\ ${ }^{1}$ Laboratoire de Nutrition Humaine, ${ }^{2}$ Laboratoire de Physiologie et Biologie du Sport, Université \\ d'Auvergne, Centre de Recherche en Nutrition Humaine d'Auvergne, 63009 Clermont-Ferrand; and \\ ${ }^{3}$ Institut National de la Recherche Agronomique, Unité de Recherches sur les Herbivores, 63122 \\ Saint-Genès-Champanelle, France
}

Received 17 March 2000; accepted in final form 20 September 2000

\begin{abstract}
Morio, Béatrice, Jean-François Hocquette, Christophe Montaurier, Yves Boirie, Corinne BouteloupDemange, Caroline McCormack, Nicole Fellmann, Bernard Beaufrère, and Patrick Ritz. Muscle fatty acid oxidative capacity is a determinant of whole body fat oxidation in elderly people. Am J Physiol Endocrinol Metab 280: E143-E149, 2001.- - In sedentary elderly people, a reduced muscle fatty acid oxidative capacity (MFOC) may explain a decrease in whole body fat oxidation. Eleven sedentary and seven regularly exercising subjects $(65.6 \pm 4.5 \mathrm{yr})$ were characterized for their aerobic fitness [maximal $\mathrm{O}_{2}$ uptake $\left(\dot{\mathrm{V}}_{2}{ }_{2}\right) / \mathrm{kg}$ fat free mass $\left.(\mathrm{FFM})\right]$ and their habitual daily physical activity level [free-living daily energy expenditure divided by sleeping metabolic rate $\left.\left(\mathrm{DEE}_{\mathrm{FLC}} / \mathrm{SMR}\right)\right]$. MFOC was determined by incubating homogenates of vastus lateralis muscle with $\left[1-{ }^{14} \mathrm{C}\right]$ palmitate. Whole body fat oxidation was measured by indirect calorimetry over $24 \mathrm{~h}$. MFOC was $40.4 \pm 14.7$ and $44.3 \pm 16.3 \mathrm{nmol}$ palmitate $\mathrm{g}$ wet tissue $^{-1} \cdot \min ^{-1}$ in the sedentary and regularly exercising individuals, respectively ( $P=$ nonsignificant). MFOC was positively correlated with $\mathrm{DEE}_{\mathrm{FLC}} / \mathrm{SMR}(r=0.58, P<0.05)$ but not with $\dot{\mathrm{V}}_{2}$ max $/ \mathrm{kg}$ FFM ( $r=0.35, P=$ nonsignificant). MFOC was the main determinant of fat oxidation during all time periods including physical activity. Indeed, MFOC explained 19.7 and $30.5 \%$ of the variance in fat oxidation during walking and during the alert period, respectively $(P<0.05)$. Furthermore, MFOC explained $23.0 \%$ of the variance in fat oxidation over $24 \mathrm{~h}(P<0.05)$. It was concluded that, in elderly people, MFOC may be influenced more by overall daily physical activity than by regular exercising. MFOC is a major determinant of whole body fat oxidation during physical activities and, consequently, over $24 \mathrm{~h}$.

habitual physical activity; endurance training; indirect calorimetry; vastus lateralis muscle
\end{abstract}

THE INCREASE IN FAT MASS observed during aging (13) results from an imbalance between fat intake and fat utilization. Fat intake does not seem to increase with aging $(11,26)$; by contrast, fat utilization may decrease with advancing age. Indeed, whole body fat oxidation

\footnotetext{
Address for reprint requests and other correspondence: B. Morio, Laboratoire de Nutrition Humaine, BP 321, 58 rue Montalembert, 63009 Clermont-Ferrand cedex 1, France (E-mail: morio@clermont. inra.fr).
}

was shown to be lower in elderly people compared with young adults after meal ingestion (20), during moderate-intensity exercise (32), and at rest in some studies $(7,8)$, but not all $(5,16)$.

Part of the age-related defect in fat oxidation may be explained by decreasing physical activity. In fact, combined results from the literature suggest that regular physical training prevents the changes in age-related fuel metabolism. Hence, the defect in fat oxidation during exercise observed in elderly people compared with young adults almost disappeared after $16 \mathrm{wk}$ of endurance training (33). Moreover, Horber et al. (18) have shown that, compared with young adults, fat oxidation at rest was significantly lower in sedentary elderly men but not in endurance-trained elderly men. Finally, endurance training was shown to stimulate fat oxidation at rest in sedentary elderly people (28), albeit in a time- or intensity-dependent manner (23).

The mechanisms of alterations in fat oxidation are still not clear. Part of the changes in fat oxidation could be explained by changes in muscle mass, e.g., agerelated loss (7) or training-induced gain $(23,28)$. However, differences in fat oxidation still exist when body composition is taken into account $(18,23,33)$. This suggests a defect of fat oxidation intrinsic to muscle.

In this respect, it has been suggested that the decrease in fat oxidation during exercise may be caused by a reduced capacity of muscle to oxidize fatty acids (33). This defect has been reported in young sedentary men (compared with young athletes) and has been explained by a reduced long-chain fatty acid entry into the mitochondria (34). However, it has not been shown at rest and/or in elderly subjects.

Changes in the capacity of muscle to oxidize fatty acids have often been assessed using the maximal activity of $\beta$-hydroxy-acyl-CoA dehydrogenase (HAD) as an indicator of the mitochondrial $\beta$-oxidation pathway $(1,10)$. However, the maximal activity of a single

\footnotetext{
The costs of publication of this article were defrayed in part by the payment of page charges. The article must therefore be hereby marked "advertisement" in accordance with 18 U.S.C. Section 1734 solely to indicate this fact.
} 
enzyme operating within a complex pathway is unlikely to represent the entire process (3). In fact, other limiting factors, such as the activity of carnitine palmitoyltransferase I (CPT-I) and that of the tricarboxylic acid cycle could modulate muscle fatty acid oxidative capacity (17). For these reasons, we chose, in the present study, to assess the maximal activity of the overall fatty acid oxidation pathway in muscle using an ex vivo method. This technique is based on the incubation of fresh muscle homogenates with $\left[1-{ }^{14} \mathrm{C}\right]$ palmitate as a substrate $(27,39)$.

Thus the present study was aimed at determining 1) whether the muscle fatty acid oxidative capacity of elderly subjects was modulated by physical activity and 2) whether any changes in muscle fatty acid oxidative capacity had significant consequences on the main components of 24 -h whole body fat oxidation, e.g., exercise, alert period, and sleep. Two levels of physical activity were taken into account: exercise status and habitual physical activity level. For that purpose, the subjects were recruited based on their self-reported time spent exercising per week, i.e., either they did not participate in any regular endurance exercise program or they regularly exercised by walking, running, cycling, and/or swimming $\geq 5 \mathrm{~h} / \mathrm{wk}$. Thereafter, each subject had his or her level of daily physical activity determined over 3 days in free-living conditions.

\section{SUBJECTS AND METHODS}

\section{Subjects and General Study Design}

Subjects. Eighteen healthy elderly people participated in the study. Eleven subjects ( 7 men and 4 women, $65.8 \pm 4.2$ yr) were sedentary, i.e., they did not participate in any regular endurance exercise program. Seven subjects (5 men and 2 women, $65.4 \pm 4.5 \mathrm{yr}$ ) regularly exercised by walking, running, cycling, and/or swimming $\geq 5 \mathrm{~h} / \mathrm{wk}$. All subjects had taken a medical examination; they were nonsmokers, were not suffering from any diagnosed disease, and were under no medication known to influence energy metabolism. All women were postmenopausal. The Medical School Ethics Committee for Biomedical Research approved the study.

General study design. The subjects completed an activity questionnaire and performed a maximal aerobic power test. Kinetics of heart rate were recorded over 3 days (from Friday to Sunday) in free-living conditions. Thereafter, the volunteers were placed on a controlled diet 2 days before and throughout the measurement period. For that purpose, eight daily menus (35\% of energy as lipids, $50 \%$ as carbohydrates, $15 \%$ as proteins) were determined individually according to each subject's basal metabolic rate predicted (4) from his or her body composition [determined from bioelectrical impedance analysis measurements (37)] and daily activities (known from the activity questionnaire) by use of the factorial method (24). Recipes were simple and detailed precisely for the volunteers to cook easily. The following measurements were performed on separate days during the dietcontrolled period: body composition [dual-energy X-ray absorptiometry (DEXA) scan; see Body composition measurements], muscle biopsy, and 36 -h whole body indirect calorimetry.

\section{Subjects Characterization}

Activity questionnaire, maximal aerobic power test, and heart rate recordings. The Baecke activity questionnaire (2) was used to calculate the time spent exercising per week and to determine the type of activities performed on a weekly basis.

The maximal aerobic power tests were all performed on the same cycloergometer (Ergomeca, Monark, Sweden) under cardiovascular supervision by a cardiologist, with use of the protocol described recently (23). Maximal oxygen uptake

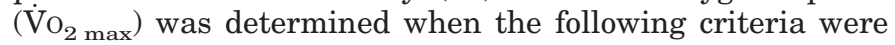
reached: a plateau in oxygen consumption, a respiratory quotient $>1.1$, and a maximal heart rate close to the theoretical maximal heart rate [220 - age (yr)].

The physical activity level (including housework and leisure and sports activities) was characterized by the ratio of free-living daily energy expenditure $\left(\mathrm{DEE}_{\mathrm{FLC}}\right)$ over sleeping metabolic rate (SMR; DEE $\mathrm{FLC}_{\mathrm{C}} / \mathrm{SMR}$; see Ref. 21). $\mathrm{DEE}_{\mathrm{FLC}}$ was determined using the heart rate recording method as described recently (24). Briefly, heart rate was recorded minute-by-minute using telemetry (Polar Protrainer, Polar Electro, Oy, Finland) during 3 days, from Friday morning until Sunday night. Energy expenditure was calculated from these recordings by means of individual relationships set up between heart rate and energy expenditure measured in the calorimeters (24). SMR was measured in the calorimeters.

Body composition measurements. Body mass was measured to the nearest $0.1 \mathrm{~kg}$ on a SECA 709 scale (SECA, Les Mureaux, France). Height was measured to the nearest 0.2 $\mathrm{cm}$. A total body scan was performed using DEXA (Hologic QDR 4501, Hologic, Waltham, MA) for determination of total and regional (arms, legs, and trunk) body composition. Fat free mass (FFM) was calculated as the sum of lean mass, soft tissue, and bone mineral content (36).

\section{Muscle Biopsy and Assays}

Materials. $\left[1-{ }^{14} \mathrm{C}\right]$ palmitic acid was purchased from Amersham International (Bucks, UK). ATP, $\mathrm{NAD}^{+}$, and cytochrome $c$ were supplied by Boeringer Mannheim (Meylan, France). Acetyl-coenzyme A, fatty acid-free bovine serum albumin, L-carnitine, palmitic acid, oxaloacetate, L-malate, and coenzyme A were purchased from Sigma (St. Louis, MO). Other chemicals used were of the highest grade commercially available.

Muscle biopsy and assay of palmitate oxidation capacity. Biopsies (60-120 mg) were obtained from the vastus lateralis muscle at 0800 after one night of fasting. Tissue was cut into pieces and cooled in ice-cold buffer consisting of $0.25 \mathrm{M}$ sucrose, $2 \mathrm{mM}$ EDTA, and $10 \mathrm{mM}$ Tris $\cdot \mathrm{HCl}(\mathrm{pH}$ 7.4). Muscle homogenate $(5 \% \mathrm{wt} / \mathrm{vol})$ was rapidly prepared in the same buffer by hand homogenization with a glass-glass homogenizer $(27,39)$. Two pestles with different diameters were used (intervening space 0.050 and $0.075 \mathrm{~mm}$ ). Palmitate oxidation rate was measured using sealed vials in a medium ( $\mathrm{pH}$ 7.4) containing (in $\mathrm{mM}$ ): 25 sucrose, 75 Tris $\cdot \mathrm{HCl}, 10$ $\mathrm{K}_{2} \mathrm{HPO}_{4}, 5 \mathrm{MgCl}_{2}$, and $1 \mathrm{EDTA}$ supplemented with $1 \mathrm{NAD}^{+}$, 5 ATP, 0.1 coenzyme A, 0.5 L-malate, 0.5 L-carnitine, and 25 $\mu \mathrm{M}$ cytochrome $c$ (39). All assays were performed in triplicate under conditions that were optimal with respect to time and concentration of palmitate and of tissue material $(27,39)$. After 5 min of preincubation at $37^{\circ} \mathrm{C}$ with shaking, the reaction was started by addition of $100 \mu \mathrm{l}$ of $600 \mu \mathrm{M}$ $\left[1-{ }^{14} \mathrm{C}\right]$ palmitate bound to albumin in a 5:1 molar ratio. The final incubation volume was thus $0.5 \mathrm{ml}$, containing $75 \mu \mathrm{l}$ of muscle homogenate. The oxidation proceeded for $30 \mathrm{~min}$ at $37^{\circ} \mathrm{C}$ and was stopped by addition of $0.2 \mathrm{ml}$ of $3 \mathrm{M}$ perchloric 
acid. The released ${ }^{14} \mathrm{CO}_{2}$ was trapped in $0.3 \mathrm{ml}$ ethanolamine-ethylene glycol $(1: 2 \mathrm{vol} / \mathrm{vol})$ and measured by liquid scintillation counting in $5 \mathrm{ml}$ of Ready Safe (Beckman Instruments, Fullerton, CA). After $90 \mathrm{~min}$ at $4^{\circ} \mathrm{C}$, the acid incubation mixture was centrifuged for $5 \mathrm{~min}$ at $10,000 \mathrm{~g}$, and the 0.5 -ml supernatant containing ${ }^{14} \mathrm{C}$-labeled perchloric acidsoluble products was assayed for radioactivity by liquid scintillation. Total palmitate oxidation rate was calculated from the sum of ${ }^{14} \mathrm{CO}_{2}$ and ${ }^{14} \mathrm{C}$-labeled acid-soluble products (39) and expressed in nanomoles palmitate per gram of wet tissue per minute.

Analytical assays. HAD, cytochrome $c$ oxidase, and citrate synthase activities were assayed spectrophotometrically on the above muscle homogenates as described previously $(6,27$, 39). One unit of enzyme is defined as the amount that catalyzes the oxidation of $1 \mu \mathrm{mol} / \mathrm{min}$ of cytochrome $c$ for cytochrome $c$ oxidase (at $25^{\circ} \mathrm{C}$ ), the liberation of $1 \mu \mathrm{mol} / \mathrm{min}$ of coenzyme A for citrate synthase (at $25^{\circ} \mathrm{C}$ ), and the disappearance of $1 \mu \mathrm{mol} / \mathrm{min}$ of $\mathrm{NADH}$ for $\mathrm{HAD}\left(\right.$ at $30^{\circ} \mathrm{C}$ ).

\section{Measurements in the Calorimeters}

Activity program and food intakes in the calorimeters. The activity program in the calorimeters consisted of four periods of 30 min each of walking at $50 \% \mathrm{VO}_{2}$ max. Food energy supply was calculated individually using the factorial method (22). For that purpose, daily energy expenditure was calculated from the duration and the energy cost of the various activities in the calorimeters (e.g., walking) (24), and a predicted basal metabolic rate was calculated from each subject's body composition (4). Food energy supply provided $50 \%$ of energy as carbohydrates, $35 \%$ as lipids, and $15 \%$ as proteins.

Indirect calorimetry measurements. Respiratory gas exchanges were measured continuously using two open-circuit whole body calorimetric chambers, as described recently (2124). Gas analyzers were calibrated upon commencement, after $13 \mathrm{~h}$ (evening), and at the end of the 24-h measurement period with the use of standard gas mixtures. Gas exchanges were computed from the minute-by-minute measurement of outlet air flow, differences in gas concentrations, atmospheric pressure, chamber air temperature and hygrometry, and by taking into account the gas analyzer's drifts and the variations of the volumes of $\mathrm{CO}_{2}$ and $\mathrm{O}_{2}$ in the chambers. The validity of gas exchange measurements was checked gravimetrically, comparing the amounts of gases $\left(\mathrm{CO}_{2}, \mathrm{O}_{2}\right)$ analyzed and those expected from the weights of gases $\left(\mathrm{CO}_{2}, \mathrm{~N}_{2}\right)$ injected into the chambers during a 24-h period (40). The recovery was $96.9 \pm 0.1 \%$ for $\mathrm{O}_{2}$ and $100.1 \pm 1.0 \%$ for $\mathrm{CO}_{2}$.

Urine was collected over $24 \mathrm{~h}$, partitioned into two periods (alert period, from 0700 to 1100 , and sleep, from 2300 to 0700) for the determination of urinary nitrogen excretion. Energy expenditure was calculated using Weir's equation (41) from the minute-by-minute measurement of gas exchanges, corrected for urinary nitrogen excretion. Daily energy balance was calculated from the difference between daily energy intake and daily energy expenditure and was expressed as percent daily energy expenditure.

Four time periods were determined: 1$)$ walking $(4 \times 30$ min), 2) alert period (from 0700 to 1100), 3) sleep (from 2300 to 0700 ), and 4) $24 \mathrm{~h}$ (from 0700 to 0700 ). Fat oxidation was calculated from gas exchanges and urinary nitrogen excretion over the periods of interest by use of Ferrannini's equations (12). In particular, respiratory gas exchanges during walking were determined over the last $20 \mathrm{~min}$ of each session. Gas exchanges during sleep were computed during the 2 nd night in the calorimeters, over $5-6 \mathrm{~h}$ after the $2 \mathrm{nd} \mathrm{h}$ after which the subjects had gone to bed, as described recently (21-24).

\section{Statistical Analyses}

Results are reported as means \pm SD. The Mann-Whitney $U$-test was used for comparison of means between sedentary and regularly exercising subjects' characteristics, body composition, muscle palmitate oxidative capacity, and fat oxidation. Normality of the data was tested using the $\chi^{2}$ test. Stepwise regressions were performed to determine which variables among daily energy balance, $\mathrm{FFM}, \dot{\mathrm{V}}_{2}$ max , and muscle palmitate oxidative capacity contributed independently to variation in fat oxidation. Correlation coefficients are Pearson product-moment correlations. Results were considered statistically significant at the $5 \%$ level.

\section{RESULTS}

\section{Subject Characteristics}

Subject characteristics, physical capacity, and body composition are given in Table 1 . The aerobic fitness $\left(\dot{\mathrm{VO}}_{2 \text { max }} / \mathrm{kg} \mathrm{FFM}\right)$, but not the physical activity level $\left(\mathrm{DEE}_{\mathrm{FLC}} / \mathrm{SMR}\right)$, was significantly lower in the sedentary subjects than in the regularly exercising subjects $(P<0.001)$. There were no significant differences between sedentary and regularly exercising subjects for age and height. Body mass and fat mass were 12.7 and $32.0 \%$ higher in the sedentary group than in the regularly exercising subjects, respectively $(P=0.10$ and $P<0.05$ ). FFM and appendicular muscle mass were similar between the two groups.

\section{Muscle Metabolic Activity}

Muscle enzyme activities. The maximal activity of HAD and cytochrome $c$ oxidase tended to be higher in regularly exercising subjects than in their sedentary counterparts, but the differences did not reach the level of significance $(3.48 \pm 0.70$ vs. $2.78 \pm 0.80, P=$ 0.06 , and $23.9 \pm 11.13$ vs. $15.09 \pm 4.89, P=0.08$, respectively). The maximal activity of citrate synthase was not significantly different between the two groups $[4.07 \pm 1.92$ vs. $3.32 \pm 1.07, P=$ not significant (NS)]

Table 1. Subject characteristics according to their exercise status

\begin{tabular}{lcc}
\hline \hline & \multicolumn{2}{c}{ Subjects } \\
\cline { 2 - 3 } & Sedentary & Regularly exercising \\
\hline Age, yr & $65.8 \pm 4.2$ & $65.4 \pm 4.5$ \\
VO $_{2 m a x}, \mathrm{ml} \cdot \mathrm{kg} \mathrm{FFM}^{-1} \cdot \mathrm{min}^{-1}$ & $38.5 \pm 4.7$ & $44.5 \pm 3.1^{*}$ \\
$\mathrm{DEE}_{\mathrm{FLC}} / \mathrm{SMR}$ & $1.70 \pm 0.29$ & $1.73 \pm 0.24$ \\
$\mathrm{Height}, \mathrm{cm}$ & $171.1 \pm 10.7$ & $168.6 \pm 7.0$ \\
Body mass, kg & $77.3 \pm 11.0$ & $68.6 \pm 7.9$ \\
FFM, kg & $56.6 \pm 12.4$ & $53.0 \pm 9.7$ \\
Appendicular muscle mass, $\mathrm{kg}$ & $24.2 \pm 6.2$ & $22.6 \pm 5.1$ \\
Fat mass, kg & $20.6 \pm 5.6$ & $15.6 \pm 3.2 \dagger$ \\
\hline
\end{tabular}

Results are means \pm SD for 11 sedentary ( 7 men, 4 women) and 7 regularly exercising (5 men, 2 women) subjects; $\mathrm{DEE} \mathrm{FLC}_{\mathrm{F}} / \mathrm{SMR}$, ratio of daily energy expenditure determined in free-living conditions $\left(\mathrm{DEE}_{\mathrm{FLC}}\right)$ over sleeping metabolic rate $(\mathrm{SMR})$, measured in calorimeters; FFM, fat-free mass; $\dot{\mathrm{V}}_{2}$ max , maximal $\mathrm{O}_{2}$ uptake. Significantly different from sedentary subjects: $* P<0.001, \dagger P<0.05$. 


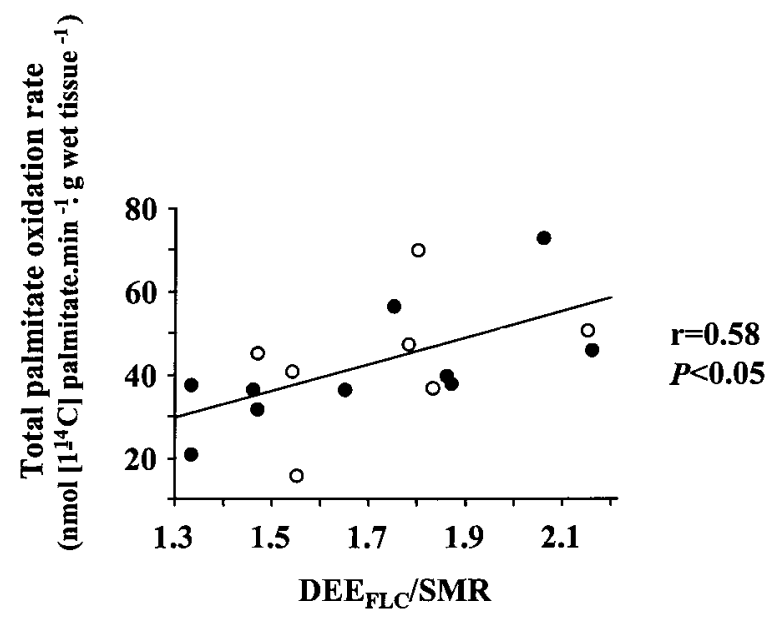

Fig. 1. Correlation between muscle palmitate oxidative capacity and the index of daily physical activity [free-living daily energy expenditure divided by sleeping metabolic rate $\left.\left(\mathrm{DEE}_{\mathrm{FLC}} / \mathrm{SMR}\right)\right]$ in 11 sedentary $(\bullet)$ and 7 regularly exercising $(\circ)$ elderly people.

Maximal activity of HAD was not significantly correlated to $\mathrm{DEE}_{\mathrm{FLC}} / \mathrm{SMR}$ or to $\dot{\mathrm{V}}_{\mathrm{O}_{2} \text { max }} / \mathrm{kg} \mathrm{FFM}(r=0.20$ and 0.14 , respectively, $P=\mathrm{NS}$ ). Maximal activity of citrate synthase and cytochrome $c$ oxidase was positively correlated with $\mathrm{V}_{2}$ max $/ \mathrm{kg}$ FFM $(r=0.42$ and 0.57 , respectively, $P<0.05$ ) but not with $\mathrm{DEE}_{\mathrm{FLC}} / \mathrm{SMR}$ $(r=-0.18$ and -0.07 , respectively, $P=\mathrm{NS})$.

Muscle palmitate oxidative capacity. Muscle palmitate oxidative capacity (i.e., total oxidation rate of palmitate) was $44.3 \pm 16.3$ and $40.4 \pm 14.7 \mathrm{nmol}$ palmitate $\cdot g$ wet tissue ${ }^{-1} \cdot \mathrm{min}^{-1}$ in the regularly exercising and sedentary groups, respectively $(P=\mathrm{NS})$. Muscle palmitate oxidative capacity was positively correlated with $\mathrm{DEE}_{\mathrm{FLC}} / \mathrm{SMR}(r=0.58, \mathrm{P}<0.05$; Fig. 1) but not with $\dot{\mathrm{V}}_{2}$ max $/ \mathrm{kg}$ FFM $(P=\mathrm{NS})$.

\section{Whole Body Fat Oxidation}

Measurements in the calorimeters. Energy expenditure $\left(\mathrm{kJ} / \mathrm{h}\right.$ and $\left.\mathrm{kJ} \cdot \mathrm{kg} \mathrm{FFM}{ }^{-1} \cdot \mathrm{h}^{-1}\right)$ and daily energy balance were not significantly different between the two groups. Fat oxidation $(\mathrm{mg} / \mathrm{h})$ was not significantly different between the two groups $(P=\mathrm{NS})$. When differences in FFM were taken into account, fat oxidation $\left(\mathrm{mg} \cdot \mathrm{kg} \mathrm{FFM}{ }^{-1} \cdot \mathrm{h}^{-1}\right)$ was slightly higher in the regularly exercising subjects than in the sedentary group at all measurement times, but the differences did not reach the level of significance ( $P$ ranged from 0.08 to 0.15 ; Table 2).

Determinants of whole body fat oxidation. Fat oxidation was always significantly correlated to daily energy balance $(r=-0.42,-0.50,-0.69$, and -0.62 during walking, alert period, sleep, and over $24 \mathrm{~h}$, respectively, $P<0.05$ ), FFM ( $r=0.36,0.47,0.48$, and 0.53 during walking, alert period, sleep, and over $24 \mathrm{~h}$, respectively, $P<0.05$ except during walking, $P=\mathrm{NS}$ ), and $\dot{\mathrm{V}}_{2 \text { max }}(r=0.52,0.56,0.56$, and 0.63 during walking, alert period, sleep, and over $24 \mathrm{~h}$, respectively, $P<0.05$ ). Stepwise regressions showed that $\dot{\mathrm{V}} \mathrm{O}_{2}$ max was a better determinant of fat oxidation than
Table 2. Results obtained from 24-h measurements in calorimeters

\begin{tabular}{|c|c|c|}
\hline & \multicolumn{2}{|c|}{ Subjects } \\
\hline & Sedentary & Regularly exercising \\
\hline \multicolumn{3}{|l|}{ Fat oxidation, $\mathrm{g} / \mathrm{h}$} \\
\hline During walking & $7.16 \pm 1.91$ & $9.09 \pm 2.84$ \\
\hline During alert period & $4.39 \pm 1.13$ & $5.83 \pm 2.56$ \\
\hline During sleep & $2.67 \pm 0.87$ & $3.33 \pm 1.78$ \\
\hline Over $24 \mathrm{~h}$ & $3.81 \pm 0.88$ & $4.70 \pm 1.37$ \\
\hline \multicolumn{3}{|l|}{ Energy expenditure, kJ/h } \\
\hline During walking & $296.8 \pm 54.2$ & $334.4 \pm 69.8$ \\
\hline During alert period & $540.7 \pm 68.6$ & $550.9 \pm 92.5$ \\
\hline During sleep & $270.4 \pm 45.0$ & $274.1 \pm 45.8$ \\
\hline Over $24 \mathrm{~h}$ & $450.6 \pm 59.5$ & $458.6 \pm 76.2$ \\
\hline $\mathrm{DEE}_{\mathrm{CAL}} / \mathrm{SMR}$ & $1.67 \pm 0.10$ & $1.70 \pm 0.10$ \\
\hline Daily energy balance $\left(\% \mathrm{DEE}_{\mathrm{CAL}}\right)$ & $-6.9 \pm 7.6$ & $-11.3 \pm 10.1$ \\
\hline
\end{tabular}

Results are means \pm SD for 11 sedentary ( 7 men, 4 women) and 7 regularly exercising (5 men, 2 women) subjects. EE, energy expenditure; $\mathrm{DEE}_{\mathrm{CAL}}$, daily energy expenditure measured in calorimeters.

FFM at all measurement times. The amount of variance in fat oxidation explained by $\dot{\mathrm{V}}_{2}$ max is presented in Table 3. Muscle palmitate oxidative capacity was the main determinant of fat oxidation during the time periods including physical activity, i.e., during walking and during the alert period (Table 3). It explained 19.7 and $30.5 \%$ of the variance in fat oxidation during walking and during the alert period, respectively $(P<0.05$, Table 3). By contrast, muscle palmitate oxidative capacity was not a significant determinant of fat oxidation during sleep (Table 3). Finally, muscle palmitate oxidative capacity explained $23.0 \%$ of the variance of fat oxidation over $24 \mathrm{~h}(P<0.05$, Table 3$)$. These results were confirmed by use of the method described by Ravussin and Bogardus (30). After adjustment for differences in daily energy balance and $\dot{\mathrm{V}}_{2}$ max , fat oxidation residuals were significantly correlated with muscle palmitate oxidative capacity during walking $(r=0.46, P<0.05)$, during the alert period $(r=0.59$, $P<0.01)$, and over $24 \mathrm{~h}(r=0.54, P<0.05)$, but not during sleep $(r=0.04, P=\mathrm{NS})$.

\section{DISCUSSION}

The effects of physical activity on muscle fatty acid oxidative capacity and the consequences on $24-\mathrm{h}$ whole

Table 3. Significant predictors in fat oxidation

\begin{tabular}{lcccc}
\hline \hline & & \multicolumn{3}{c}{$\begin{array}{c}\text { Variance (\%) in Fat Oxidation } \\
\text { Explained by: }\end{array}$} \\
\cline { 3 - 5 } & $\begin{array}{c}\text { Total } \\
\text { Variance } \\
r^{2}\end{array}$ & $\begin{array}{c}\text { Daily energy } \\
\text { balance }\end{array}$ & $\dot{\mathrm{Vo}}_{2 \max } \begin{array}{c}\text { Muscle oxidative } \\
\text { capacity }\end{array}$ \\
\hline Fat oxidation, g/h & & & & \\
During walking & $0.516^{*}$ & $16.2^{*}$ & $15.7^{*}$ & $19.7^{*}$ \\
During alert period & $0.634 \dagger$ & $20.3^{*}$ & $12.6^{*}$ & $30.5^{*}$ \\
During sleep & $0.578^{*}$ & $36.6^{\dagger}$ & $17.8^{*}$ & $\mathrm{NS}$ \\
Over 24 h & $0.678 \ddagger$ & $26.9 \dagger$ & $17.9 \dagger$ & $23.0^{*}$ \\
\hline
\end{tabular}

$r^{2}$, Correlation coefficient derived from stepwise linear regression between fat oxidation and its predictors (daily energy balance, $\dot{\mathrm{V}}_{2 \max }$, and muscle oxidative capacity). Additional results are the amount of variance in fat oxidation explained by each significant predictor. NS, not included in the stepwise regression. Level of significance: $* P<0.05, \dagger P<0.01, \dagger P<0.001$. 
body fat oxidation were examined in elderly people. Two levels of physical activity were taken into account, the exercise status and the habitual physical activity level. For that purpose, the subjects were recruited on the basis of self-reported time spent exercising per week, i.e., either they did not participate in any regular endurance exercise program or they regularly exercised by walking, running, cycling, and/or swimming $\geq 5 \mathrm{~h} / \mathrm{wk}$. Thereafter, each subject was characterized by his or her level of daily physical activity in free-living conditions (i.e., $\mathrm{DEE}_{\mathrm{FLC}} / \mathrm{SMR}$ ). The capacity of muscle to oxidize fatty acids was assessed ex vivo from the maximal activity of the overall fatty acid oxidation pathway by use of palmitate as a substrate. Muscle maximal capacity to oxidize palmitate was not significantly affected by the exercise status. It was, however, positively correlated to $\mathrm{DEE}_{\mathrm{FLC}} / \mathrm{SMR}$ (Fig. 1). Furthermore, muscle palmitate oxidative capacity was the most important predictor of whole body fat oxidation during walking and the alert period, but not during sleep. Consequently, it was a significant predictor of whole body fat oxidation over $24 \mathrm{~h}$. It is possible that the negative energy balance during the experiments stimulated fat oxidation (including muscle palmitate oxidative capacity) in the subjects. However, because the data from the calorimeters showed no difference in energy status between the two groups, they both should have been affected similarly. Hence, the presence of a negative energy state should not change our conclusions.

Muscle maximal capacity to oxidize palmitate was determined using an ex vivo method based on the incubation of fresh muscle homogenates with $\left[1-{ }^{14} \mathrm{C}\right]$ palmitate $(27,39)$. The experiment was conducted under optimal conditions with respect to concentration of palmitate, albumin, and cofactors and to physicochemical parameters $(27,39)$. Moreover, the diameters of the pestles were adapted to minimize the degradation of the subcellular organelles with respect to peroxisomes and subsarcolemmal and intermyofibrillar mitochondria $(27,39)$. Therefore, the ex vivo technique measured, in a partially preserved cellular environment, the maximal activity of the overall fatty acid oxidation pathway.

Even though peroxisomal $\beta$-oxidation of palmitate contributes $\sim 28 \%$ to total muscle palmitate oxidative capacity (39), the latter is mainly determined from the oxidative capacity of mitochondria. Physical training has often been associated with increased maximal activity of mitochondrial oxidative enzymes in muscles of young (42) and elderly people (3). In the present study, although we did not show significant differences in the maximal activity of cytochrome $c$ oxidase and citrate synthase between the two groups, the maximal activity of these two enzymes was positively correlated to $\dot{\mathrm{V}}_{2} \mathrm{O}_{2}$ ax $/ \mathrm{kg}$ FFM. Surprisingly, we did not find any connection between exercise status and muscle palmitate oxidative capacity; the latter was similar between the two groups and was not significantly correlated to $\dot{\mathrm{V}}_{2}$ max $/ \mathrm{kg}$ FFM. Correlation analyses showed that muscle palmitate oxidative capacity was not deter- mined by the maximal activity of citrate synthase $(r=$ $0.05, P=\mathrm{NS})$ and cytochrome $c$ oxidase $(r=0.25, P=$ NS), which is in agreement with Van Hinsberg et al. (38). In contrast, it was partially determined by the maximal activity of $\operatorname{HAD}(r=0.49, P<0.05)$, which was weakly altered by the exercise status. Other factors, therefore, have to determine the maximal capacity of muscle to oxidize palmitate. For instance, the activity of the enzyme controlling the entry of fatty acids into the mitochondria (CPT-I) has been suggested to be a predominant point of control of muscle fatty acid oxidative capacity (29).

Interestingly, muscle palmitate oxidative capacity was positively correlated to $\mathrm{DEE}_{\mathrm{FLC}} / \mathrm{SMR}$. This index characterizes the intensity of the overall activity, which includes resting, housekeeping, and leisure and sports activities. $\mathrm{DEE}_{\mathrm{FLC}}$ has been calculated using the heart rate recording method. This method is based on the relationship between heart rate and energy expenditure, which is calibrated individually from the 24-h measurements in the calorimeters (24). The heart rate recording method has been validated against the doubly labeled water method in free-living elderly people (24). Mean differences in daily energy expenditure were $4-6 \%$ between the two methods (24). In the present study, the index of daily physical activity may have been partially biased, because heart rate was measured over only 3 days in free-living conditions. Because within-subject coefficient of variation of $\mathrm{DEE}_{\mathrm{FLC}}$ was shown to be only $12 \%$ in elderly men and $6 \%$ in elderly women over 14 days (24), the conclusion is likely to be still valid. Hence, the present results suggest that subjects with low daily physical activities were characterized by low muscle oxidative capacity, even if they exercised $\geq 5 \mathrm{~h} / \mathrm{wk}$. It is noteworthy that, although the subjects who exercised regularly had a significantly higher $\dot{\mathrm{V}}_{2}$ max and a lower fat mass, their daily physical activity was not significantly higher than that of sedentary subjects. In other words, there is no systematic relationship between the level of exercise and the daily physical activity. This is likely due to the fact that some of the regularly exercising subjects decrease their daily activity to compensate for the fatigue caused by exercising. This situation has already been described in sedentary elderly people after an endurance training program $(14,22)$ : the initially sedentary elderly people decreased their energy expenditure during the alert period to compensate for the additional energy cost of the training sessions. Therefore, this result suggests that, in elderly people, the training-induced stimulation of muscle fatty acid oxidative capacity may not be detected if the subjects rest during the remaining time. Conversely, it suggests that muscle fatty acid oxidative capacity may be stimulated when the elderly subjects perform physical activities of moderate intensity over a long time period. To subdivide the subjects according to their daily physical activity level, a cut-off value has to be determined. According to previous studies $(22,24)$, the $\mathrm{DEE}_{\mathrm{FLC}}$ ' SMR of elderly people averaged $\sim 1.8$. A cut-off value could be proposed at 1.7 so that, below this value, 
subjects could be considered inactive, whereas above this value, subjects could be considered "normally" active or very active. By use of this cut-off value, muscle palmitate oxidative capacity was $36.8 \%$ lower in the less active group than in the more active one (respectively, $\mathrm{DEE}_{\mathrm{FLC}} / \mathrm{SMR}=1.47 \pm 0.10$ vs. $1.92 \pm$ 0.16 , muscle palmitate oxidative capacity $=32.4 \pm$ 10.0 vs. $51.4 \pm 13.2 \mathrm{nmol}$ palmitate.g wet tissue $^{-1} \cdot \min ^{-1} ; n=9$ in each group, $P<0.05$ ). This result needs to be confirmed, however, by comparing two groups of sedentary elderly people differing from each other only by their level of daily physical activity.

As expected (23), FFM was an important determinant of whole body fat oxidation. It was, however, less pronounced than $\mathrm{V}_{2}$ max . This is likely due to the fact that $\dot{\mathrm{V}}_{2}$ max , which is strongly related to FFM, also includes the peripheral effects of exercising on the respiratory and cardiovascular systems (15) and maybe on the hormonal control of substrate metabolism $(28,31,35)$. Because muscle mass is the largest component of FFM (42\% of FFM in both males and females in the present study) and is one of the main tissues oxidizing fatty acids, it may be involved in alterations in whole body fat metabolism (43). We therefore investigated the relationships between variations in muscle fatty acid oxidative capacity and whole body fat oxidation. Implicit in the statistical evaluation (i.e., correlations) that we performed is the assumption that the ex vivo measurement of palmitate oxidation from one muscle is a good predictor of whole body muscle fatty acid oxidative capacity. The fiber composition of the vastus lateralis being mixed, this muscle was assumed to be rather representative of whole body muscle mass. But it should also be remembered that the vastus lateralis is one of the most accessible muscles for sampling in elderly humans, in whom multiple biopsies are not feasible. Hence, we found a positive relationship between muscle palmitate oxidative capacity and whole body fat oxidation during walking. We acknowledge that, since vastus lateralis muscles are solicited during walking, fatty acid oxidation capacity of this specific muscle may have greater consequences on whole body fat oxidation than that of upper-body skeletal muscles. Because substrate and $\mathrm{O}_{2}$ availability is not rate limiting during low- to moderate-intensity exercise (19), the relationship between muscle palmitate oxidative capacity and whole body fat oxidation suggests that in vivo muscle fatty acid oxidation may be rate limited by muscle-specific metabolic factors during exercise. This relationship still existed during the alert period and over $24 \mathrm{~h}$, probably because the subjects performed only moderate-intensity activities in the calorimeters. These results are in agreement with findings of Zurlo et al. (43), who showed in 14 adults that 24 -h respiratory quotient was negatively correlated with the maximal activity of $\mathrm{HAD}$ measured on vastus lateralis biopsies. Therefore, because elderly people often practice low- to moderateintensity activities in free-living conditions (24), these results suggest that their whole body fat oxidation during the alert period may be partly determined by their muscle fatty acid oxidative capacity. Especially in elderly subjects with low daily physical activities, whole body fat oxidation during the alert period may be blunted because of a low muscle fatty acid oxidative capacity. This may participate in achieving positive fat balance and thus be a factor in the increased fat mass observed with aging.

By contrast, muscle palmitate oxidative capacity was not a predictor of fat oxidation during sleep, although skeletal muscles still contribute to $\sim 43 \%$ of whole body fat oxidation in resting conditions (estimation in elderly subjects from Ref. 9). This may be due to the fact that skeletal muscle at rest has a low metabolic rate per mass unit (9), so that its fatty acid oxidation rate is not maximal. In resting conditions, whole body fuel metabolism may be determined more by hormonal control and energy balance. In fact, in the present study, $36.6 \%$ of the variance of whole body fat oxidation during sleep was explained by daily energy balance. Moreover, fat oxidation at rest in women, but to a lesser extent in men, has been significantly correlated to insulin and free thyroxine plasma concentrations (25). Finally, fat oxidation at rest may also be modulated by sympathetic nervous system activity and tissue sensitivity to catecholamines $(28,35)$.

In conclusion, in elderly people, muscle palmitate oxidative capacity may be influenced more by overall daily physical activity than by regular exercise. Furthermore, muscle palmitate oxidative capacity is a major determinant of whole body fat oxidation during moderate-intensity activities and, consequently, whole body fat oxidation during the alert period and over $24 \mathrm{~h}$. However, muscle palmitate oxidative capacity is not a determinant of whole body fat oxidation during sleep. Therefore, our results suggest that a sedentary lifestyle may be associated with a reduced muscle fatty acid oxidative capacity that may participate in decreasing whole body fat oxidation during moderate intensity activity and, consequently, over $24 \mathrm{~h}$.

The authors thank Vincent Puissant, Marion Brandolini, Liliane Morin, Paulette Rousset, Guy Manlhiot (Centre de Recherche en Nutrition Humaine), Michel Vermorel, and Nicole Guivier (Institut National de la Recherche Agronomique-Unité de Recherches sur les Herbivores) for their cooperation and skilled assistance, and Catherine W. Yeckel for reviewing the English. The authors are grateful to the volunteers for their participation in the study.

The present study was supported by the Institut National de la Recherche Agronomique and by a grant from Institut Danone.

\section{REFERENCES}

1. Aniansson A, Grimby G, and Hedberg M. Compensatory muscle fiber hypertrophy in elderly men. J Appl Physiol 73: 812-816, 1992.

2. Baecke JA, Burema J, and Frijters JE. A short questionnaire for the measurement of habitual physical activity in epidemiological studies. Am J Clin Nutr 36: 936-942, 1982.

3. Berthon P, Freyssenet D, Chatard JC, Castells J, Mujika I, Geyssant A, Guezennec CY, and Denis C. Mitochondrial ATP production rate in 55 to 73-year-old men: effect of endurance training. Acta Physiol Scand 154: 269-274, 1995.

4. Black AE, Coward WA, Cole TJ, and Prentice AM. Human energy expenditure in affluent societies: an analysis of 574 doubly-labelled water measurements. Eur J Clin Nutr 50: 72-92, 1996. 
5. Bonadonna RC, Groop LC, Simonson DC, and DeFronzo RA. Free fatty acid and glucose metabolism in human aging: evidence for operation of the Randle cycle. Am J Physiol Endocrinol Metab 266: E501-E509, 1994.

6. Brdiczka D, Gerbitz K, and Pette D. Localization and function of external and internal carnitine acetyltransferases in mitochondria of rat liver and pig kidney. Eur J Biochem 11: 234-240, 1969.

7. Calles-Escandon J, Arciero PJ, Gardner AW, Bauman C, and Poehlman ET. Basal fat oxidation decreases with aging in women. J Appl Physiol 78: 266-271, 1995.

8. Calles-Escandon J, Poehlman ET, and Garcia-Rubi E. Lipolysis in elderly postmenopausal women. Metabolism 46: 1312$1315,1997$.

9. Elia M. Organ and tissue contribution to metabolic rate. In: Energy Metabolism: Tissue Determinants and Cellular Corollaries, edited by JM Kinney and HN Tucker. New York: Raven, 1992, p. 61-79.

10. Essen-Gustavsson $\mathbf{B}$ and Borges O. Histochemical and metabolic characteristics of human skeletal muscle in relation to age. Acta Physiol Scand 126: 107-114, 1986.

11. Euronut investigators SENECA. Summary and recommendations for further analysis. Eur J Clin Nutr 45: 183-185, 1991.

12. Ferrannini E. The theoretical bases of indirect calorimetry: a review. Metabolism 37: 287-301, 1988.

13. Flynn MA, Nolph GB, Baker AS, Martin WM, and Krause G. Total body potassium in aging humans: a longitudinal study. Am J Clin Nutr 50: 713-717, 1989.

14. Goran MI and Poehlman ET. Endurance training does not enhance total energy expenditure in healthy elderly persons. Am J Physiol Endocrinol Metab 263: E950-E957, 1992.

15. Grimby G. Physical activity and effects of muscle training in the elderly. Ann Clin Res 20: 62-66, 1988.

16. Gumbiner B, Thorburn AW, Ditzler TM, Bulacan F, and Henry RR. Role of impaired intracellular glucose metabolism in the insulin resistance of aging. Metabolism 41: 1115-1121, 1992.

17. Hocquette JF and Bauchart D. Intestinal absorption, blood transport and hepatic and muscle metabolism of fatty acids in preruminant and ruminant animals. Reprod Nutr Dev 39: 2748, 1999.

18. Horber FF, Kohler SA, Lippuner K, and Jaeger P. Effect of regular physical training on age-associated alteration of body composition in men. Eur J Clin Invest 26: 279-285, 1996.

19. Jeukendrup AE, Saris WH, and Wagenmakers AJ. Fat metabolism during exercise: a review. Part I: fatty acid mobilization and muscle metabolism. Int J Sports Med 19: 231-244, 1998.

20. Melanson KJ, Saltzman E, Russell RR, and Roberts SB. Fat oxidation in response to four graded energy challenges in younger and older women. Am J Clin Nutr 66: 860-866, 1997.

21. Morio B, Beaufrère B, Montaurier C, Verdier E, Ritz P, Fellmann N, Boirie Y, and Vermorel M. Gender differences in energy expended during activities and in daily energy expenditure of elderly people. Am J Physiol Endocrinol Metab 273: E321-E327, 1997.

22. Morio B, Montaurier C, Pickering G, Ritz P, Fellmann N, Coudert J, Beaufrère B, and Vermorel M. Effects of $14 \mathrm{wk}$ of progressive endurance training on energy expenditure in elderly people. Br J Nutr 80: 511-519, 1998.

23. Morio B, Montaurier C, Ritz P, Fellmann N, Coudert J, Beaufrère B, and Vermorel $\mathbf{M}$. Time-course effects of endurance training on fat oxidation in sedentary elderly people. Int $J$ Obes Relat Metab Disord 23: 706-714, 1999.

24. Morio B, Ritz P, Verdier E, Montaurier C, Beaufrère B, and Vermorel M. Critical evaluation of the factorial and heartrate recording methods for the determination of energy expenditure of free-living elderly people. Br J Nutr 78: 709-722, 1997.

25. Nagy TR, Goran MI, Weinsier RL, Toth MJ, Schutz Y, and Poehlman ET. Determinants of basal fat oxidation in healthy Caucasians. J Appl Physiol 80: 1743-1748, 1996.
26. Ortega RM, Requejo AM, Andres P, Lopez-Sobaler AM, Quintas ME, Redondo MR, Navia B, and Rivas T. Dietary intake and cognitive function in a group of elderly people. $A m J$ Clin Nutr 66: 803-809, 1997.

27. Piot C, Veerkamp JH, Bauchart D, and Hocquette JF. Contribution of mitochondria and peroxisomes to palmitate oxidation in rat and bovine tissues. Comp Biochem Physiol B Biochem Mol Biol 12: 185-194, 1998.

28. Poehlman ET, Gardner AW, Arciero PJ, Goran MI, and Calles-Escandon J. Effects of endurance training on total fat oxidation in elderly persons. J Appl Physiol 76: 2281-2287, 1994.

29. Rasmussen BB and Wolfe RR. Regulation of fatty acid oxidation in skeletal muscle. Annu Rev Nutr 19: 463-484, 1999.

30. Ravussin E and Bogardus C. Relationship of genetics, age, and physical fitness to daily energy expenditure and fuel utilization. Am J Clin Nutr 49: 968-975, 1989.

31. Romijn JA, Coyle EF, Sidossis LS, Gastaldelli A, Horowitz JF, Endert E, and Wolfe RR. Regulation of endogenous fat and carbohydrate metabolism in relation to exercise intensity and duration. Am J Physiol Endocrinol Metab 265: E380-E391, 1993.

32. Sial S, Coggan AR, Carroll R, Goodwin J, and Klein S. Fat and carbohydrate metabolism during exercise in elderly and young subjects. Am J Physiol Endocrinol Metab 271: E983E989, 1996.

33. Sial S, Coggan AR, Hickner RC, and Klein S. Traininginduced alterations in fat and carbohydrate metabolism during exercise in elderly subjects. Am J Physiol Endocrinol Metab 274: E785-E790, 1998

34. Sidossis LS, Wolfe RR, and Coggan AR. Regulation of fatty acid oxidation in untrained vs. trained men during exercise. Am J Physiol Endocrinol Metab 274: E510-E515, 1998.

35. Tremblay A, Coveney S, Despres JP, Nadeau A, and Prud'homme D. Increased resting metabolic rate and lipid oxidation in exercise-trained individuals: evidence for a role of $\beta$-adrenergic stimulation. Can J Physiol Pharmacol 70: 1342$1347,1992$.

36. Treuth MS, Ryan AS, Pratley RE, Rubin MA, Miller JP, Nicklas BJ, Sorkin J, Harman SM, Goldberg AP, and Hurley BF. Effects of strength training on total and regional body composition in older men. J Appl Physiol 77: 614-620, 1994.

37. Vache C, Rousset P, Gachon P, Gachon AM, Morio B, Boulier A, Coudert J, Beaufrère B, and Ritz P. Bioelectrical impedance analysis measurements of total body water and extracellular water in healthy elderly subjects. Int $J$ Obes Relat Metab Disord 22: 537-543, 1998.

38. Van Hinsbergh VW, Veerkamp JH, and Van Moerkerk HT. Cytochrome $c$ oxidase activity and fatty acid oxidation in various types of human muscle. J Neurol Sci 47: 79-91, 1980.

39. Veerkamp JH, Van Moerkerk HT, Glatz JF, and Van Hinsbergh VW. Incomplete palmitate oxidation in cell-free systems of rat and human muscles. Biochim Biophys Acta 753: 399-410, 1983

40. Vermorel M, Bitar A, and Vernet J. Calorimetrie indirecte. 3. Controle de la validité des mésures des échanges gazeux respiratoires des animaux et des humains (Control of the respiratory exchange measurement validity in animals and human beings). Cah Tech INRA 35: 63-76, 1995.

41. Weir JB. New methods for calculating metabolic rate with special reference to protein metabolism. J Physiol (Lond) 109: $1-9,1949$.

42. Wibom R, Hultman E, Johansson M, Matherei K, Constantin-Teodosiu D, and Schantz PG. Adaptation of mitochondrial ATP production in human skeletal muscle to endurance training and detraining. J Appl Physiol 73: 2004-2010, 1992.

43. Zurlo F, Nemeth PM, Choksi RM, Sesodia S, and Ravussin E. Whole-body energy metabolism and skeletal muscle biochemical characteristics. Metabolism 43: 481-486, 1994. 